\title{
Preclinical Safety Evaluation of Intravitreal Injection of Full-Length Humanized Vascular Endothelial Growth Factor Antibody in Rabbit Eyes
}

\author{
$\ddot{U}$ mit Übeyt Inan, ${ }^{1}$ Berrin Avci, ${ }^{2}$ Tuncay Kusbeci, ${ }^{1}$ Berkant Kaderli, ${ }^{3}$ Remzi Avci, ${ }^{3}$ and \\ Sebime G. Temel ${ }^{4}$
}

Purpose. To evaluate the preclinical safety of intravitreal bevacizumab, which is a full-length humanized monoclonal antibody against the vascular endothelial growth factor (VEGF), in rabbit eyes over a short-term period.

Methods. Twenty-four rabbits were divided into two groups, each with two subgroups. The first group (groups 1 and 2) received $1.25 \mathrm{mg}(0.05 \mathrm{~mL})$ intravitreal bevacizumab, and the second group (groups 3 and 4) received $3.00 \mathrm{mg}(0.12 \mathrm{~mL})$ intravitreal bevacizumab. The right eyes were designated as the study eyes, and the left eyes served as a control and received the same volume of saline intravitreally. Groups 1 and 3 were labeled as early groups and scheduled to be terminated at 14 days. Groups 2 and 4, labeled as late groups, were scheduled to be terminated at 28 days. Besides electroretinography (ERG) and visually evoked potentials (VEP), central corneal thickness, intraocular pressure, fundus photography, and anterior segment imaging were performed at baseline and scheduled time points. Enucleated eyes were preserved for light and electron microscopic investigation.

Results. No anterior segment inflammation was observed, except in one eye in group 1 which showed a uveitic reaction. No evidence of retinal toxicity was seen with intravitreal bevacizumab at doses of 1.25 and $3.00 \mathrm{mg}$, by either ERG or light microscopy. Electron microscopic assessment revealed mitochondrial damage in the inner segments of photoreceptors. Immunohistochemical staining with bax and caspase- 3 and -9 showed intensive apoptotic protein expression in all study sections and minimal expression in the control eyes.

Conclusions. Although electrophysiologic investigation and light microscopy showed normal retinal function and structure, mitochondrial disruption in the inner segments of photoreceptors was detected by electron microscopy, and apoptotic expression was detected after the injection of intravitreal bevacizumab. (Invest Ophthalmol Vis Sci. 2007;48: 1773-1781) DOI:10.1167/iovs.06-0828

$\mathrm{V}$ ascular endothelial growth factor (VEGF) has been identified as an endothelial cell-specific mitogen and angiogenic inducer in vivo. VEGF has been implicated as the major angiogenic stimulus responsible for intraocular neovascularization in

From the ${ }^{1}$ Department of Ophthalmology, Kocatepe University School of Medicine, Afyon, Turkey; and the Departments of ${ }^{2}$ Histology and Embryology, ${ }^{3}$ Ophthalmology, and ${ }^{4}$ Medical Genetics, Uludag University School of Medicine, Bursa, Turkey.

Submitted for publication July 19, 2006; revised November 7 , 2006; accepted February 19, 2007.

Disclosure: Ü.Ü. İnan, None; B. Avci, None; T. Kusbeci, None; B. Kaderli, None; R. Avci, None; S.G. Temel, None

The publication costs of this article were defrayed in part by page charge payment. This article must therefore be marked "advertisement" in accordance with 18 U.S.C. $\$ 1734$ solely to indicate this fact.

Corresponding author: Ümit Übeyt İnan, Dumlupinar Mh Turabi Cd, Tutuncu Apt. B Blok 4/7, 03200 Afyon, Turkey; uinan@aku.edu.tr. certain ocular diseases such as proliferative diabetic retinopathy, age-related macular degeneration, retinal vascular occlusions, and other ischemic retinal diseases. ${ }^{1-12}$

Bevacizumab is a full-length humanized anti-VEGF monoclonal antibody. It is the first antiangiogenic agent approved by the Food and Drug Administration for the treatment of metastatic colorectal cancer. ${ }^{13-17}$ Bevacizumab has two binding sites, binds directly to VEGF, and has been shown to inhibit more than one of the nine VEGF isoforms. ${ }^{13-18}$

Recently, several studies have reported beneficial therapeutic effects of intravitreal injection of bevacizumab, as well as documenting its penetration into the deeper retinal layers. ${ }^{19-29}$ In no safety studies involving electron microscopy have the use of bevacizumab intraocularly and its subsequent effects been investigated. We set out to test the toxicity of intravitreal injection of bevacizumab and designed a laboratory animal study. Preclinical safety of intravitreal bevacizumab was further evaluated by electrophysiological and electron microscopic investigations as well as intraocular pressure and anterior segment assessment.

\section{Materials ANd Methods}

Full-length humanized rhumab VEGF antibody which is commercially available (bevacizumab, Avastin; Genentech Inc., San Francisco, CA) was used in the study.

\section{Animals}

All experiments in this study were conducted in accordance with the guidelines set forth by the ARVO Statement for the Use of Animals in Ophthalmic and Vision Research and with the institutional guidelines regarding animal experimentation in ophthalmic and vision research. The animals were fed standard laboratory food and allowed free access to water in an air-conditioned room with a 12-hour light-dark cycle.

Twenty-four male rabbits, 1.8 to $2.5 \mathrm{~kg}$ on the day before drug administration, were assigned to four groups $(n=6$ in each group; Table 1). The animals in groups 1 and 2 received bevacizumab with a dose of $1.25 \mathrm{mg} /$ eye through a 30 -gauge needle. The animals in groups 3 and 4 received intravitreal bevacizumab of $3.0 \mathrm{mg}$ in the right eye. The right eyes received the drug as study eyes, whereas the left eyes received the same volume of saline and served as a control group.

\section{Procedure}

Intravitreal injection of bevacizumab was performed after baseline examinations and baseline electroretinography. Before all intravitreal injections, the rabbits were anesthetized by an intramuscular combination of ketamine hydrochloride $(25 \mathrm{mg} / \mathrm{kg}$ ) and xylazine hydrochloride $(2 \mathrm{mg} / \mathrm{kg})$. The pupils were dilated with $2.5 \%$ phenylephrine hydrochloride and $10 \%$ tropicamide. After ocular surface anesthesia was administered with a topical instillation of proparacaine hydrochloride (Alcain; Alcon-Couvreur, Puurs, Belgium), the eyes were washed with several drops of $5 \%$ povidone iodide. A 30-gauge needle was introduced into the vitreous cavity, $1.5 \mathrm{~mm}$ posterior to the superotemporal limbus, and the needle tip was directed into the midvitreous 
TABLE 1. Treatment Groups

\begin{tabular}{lcccccc}
\hline Group & $\begin{array}{c}\text { Eyes } \\
(\boldsymbol{n})\end{array}$ & $\begin{array}{c}\text { ERG/VEP } \\
(\text { days })\end{array}$ & Histology & $\begin{array}{c}\text { Dose } \\
(\boldsymbol{\mu} \mathbf{g})\end{array}$ & $\begin{array}{c}\text { Dose } \\
\text { Concentrations } \\
(\mathbf{m g} / \mathbf{m L})\end{array}$ & $\begin{array}{c}\text { Dose } \\
\text { Volume } \\
(\boldsymbol{\mu} \mathbf{L})\end{array}$ \\
\hline 1 (day 14) & 6 & PI, 14 & LM/EM/IS & 1250 & 25 & 50 \\
2 (day 28) & 6 & PI, 28 & LM/EM/IS & 1250 & 25 & 50 \\
3 (day 14) & 6 & PI, 14 & LM/EM/IS & 3000 & 25 & 125 \\
4 (day 28) & 6 & PI, 28 & LM/EM/IS & 3000 & 25 & 125 \\
\hline
\end{tabular}

PI, preinjection; LM, light microscopy $(n=5)$; EM, electron microscopy $(n=1)$; ERG, electroretinography; VEP, visual evoked potentials; IS, immunohistochemical staining for apoptosis.

under direct visualization with external illumination of indirect ophthalmoscopy. A volume of 0.05 (low-dose group) or $0.12 \mathrm{~mL}$ (high-dose group) of the drug solution was then slowly administered. The needle was held in place for 10 seconds before withdrawal to prevent reflux from the entry site. The central retinal artery was observed with indirect ophthalmoscopy to be sure of patency after each injection. The other eye of each animal was used as a control. The control eyes received a volume of 0.05 or $0.12 \mathrm{~mL}$ of saline solution. Ofloxacin eye drops $0.3 \%$ (Exocin; Allergan, Dublin, Ireland) were applied to the eyes immediately after the procedure.

\section{Toxicity Assessment}

Clinical Observations. The study eyes were examined clinically before injection, 3 days after intravitreal injection, and at the end of the study. At follow-up the pupils were dilated with tropicamide eye drops. According to a prospective protocol, the following parameters were recorded: corneal clarity, transparency, appearance of the lens and retina, conjunctival reaction, proteinaceous ray, and cells in the anterior and posterior segment of the eye.

Slit Lamp Examination of the Anterior Segment. The appearance of conjunctiva and cornea were documented by slit lamp photography and an anterior segment digital imaging system (FS-3V Slit lamp; Nikon, Tokyo, Japan; and GEST BIO Explorer Imaging System; Hitas, Ankara, Turkey). The anterior chamber and anterior vitreous were examined by slit lamp under the highest magnification for evaluation of cellular reaction and flare. Before and after the injections the crystalline lens was photographed to assess any opacity that may have occurred because of the effects of intravitreal bevacizumab.

Fundus Examination. At the baseline, immediately after and 3 days after intravitreal injection, all study and control eyes were examined by indirect ophthalmoscopy and a 20-D aspherical lens to be sure of clear and sharp imaging of the retina and to exclude any possible disease in the vitreous, retina, and choroid. At the end of the experiments all eyes were documented in the standard way by fundus photography (RC-XV3; Kowa, Tokyo, Japan). Fundus fluorescein angiography was performed in randomly selected animals (one in each group) as well. Fluorescein solution $(10 \%, 1 \mathrm{~mL}$; Angiofluor; Alliance Pharmaceutical Corp., Chippenham, United Kingdom) was applied via the marginal ear vein.

IOP Measurements. To assess whether intravitreal bevacizumab causes any change in intraocular pressure, the pressure was measured in all animals at three different time points. Intraocular pressure measurements (Tonopen; Mentor Ophthalmics, Norwell, MA) were recorded before injection, immediately after injection, and at the final examination. Three consecutive measurements were taken, and the mean value of the measurements was obtained. Preinjection measurements were compared with the final measurements of the same eye and those of the contralateral eye.

Central Corneal Thickness Measurements. In addition to slit lamp examination of the cornea, central corneal thickness (CCT) was measured, to assess any effect of bevacizumab on the thickness of the cornea. Pachymetric measurements (Ultrasonic pachymeter; Quantel Medical, Clermont-Ferrand, France) were performed before and after intravitreal injections at 0,14 , and 28 days. The mean values of the corneal thickness were obtained from three consecutive measurements of the central area of the cornea.

\section{Electrophysiologic Assessment}

To assess functional alterations in sensorineural retina, retinal pigment epithelium and optic nerve, electroretinography (ERG), and visual evoked potentials (VEPs) were tested before intravitreal injection of bevacizumab, 1 day after injection, and at final examination in each group.

An electrophysiology system (Vision Monitor Electrophysiology Model MonElec2; Metrovision, Pérenchies, France) was used for ERG/ VEPs recordings. The system uses halogen light sources coupled with interferential filters that ensure a precise control of the luminance and the spectral characteristics of the stimulus and uses a mechanical shutter providing a precise control of stimulus duration suitable for flash, on, off, and flicker stimulations. Light signals were obtained from a Ganzfeld optoelectronic stimulator (Universial; Metrovision), amplified by a bioelectric signal amplifier $(\times 12.500)$ and filtered at 1 to 35 $\mathrm{Hz}$. Data were collected, stored, and analyzed using a microcomputerdesigned software and data acquisition hardware electronic control unit.

Electroretinography. Dark-adapted (scotopic) and lightadapted (photopic) ERGs were performed on all animals before the intravitreal injection to establish baseline standards. The following recordings were obtained 14 and 28 days after the injections. The contralateral eye of each rabbit served as a control for the treated eye. The rabbits were not anesthetized to avoid the effects of anesthetics on the ERG signals. Monocular recordings were performed, and contralateral eyes were occluded while the tested eye was recorded. The pupils were dilated with cyclopentolate hydrochloride $1 \%$ (Sikloplejin, Abdi Ibrahim, Turkey) and phenylephrine hydrochloride 5\% (Mydfrin; Alcon, Fort Worth, TX).

ERGs were recorded with the use of a monopolar ERG jet corneal contact lens electrode (as a positive electrode; Universo SA, La ChauxDe-Fonds, Switzerland). A drop of $0.5 \%$ proparacaine hydrochloride was instilled for corneal anesthesia, and one drop of $1 \%$ hydroxypropylmethylcellulose solution was put between the cornea and electrode. Needle electrodes were inserted subcutaneously on the head and in the neck region as reference and ground electrodes, respectively.

A standard procedure was performed with different flash intensities according to the recommendations of the International Society for Clinical Electrophysiology of Vision (scotopic: $25 \mathrm{~dB}, 0 \mathrm{~dB}$; photopic: $0 \mathrm{~dB}$ ). Scotopic 25- and 0-dB ERGs were recorded with a standard white flash without attenuation and a scotopic background. Photopic $0 \mathrm{~dB}$ ERGs were recorded with a standard white flash and a photopic background. Eight responses elicited by identical flashes applied at 10-second intervals were averaged in the dark-adapted state. In the light-adapted state, 32 responses (applied at 1-second intervals) were averaged. The rabbits were dark adapted for at least 1 hour before the scotopic recording and the photopic recordings were studied after a 
TABLE 2. Early- and Late-Term ERG Results under Scotopic and Photopic Conditions in Eyes Receiving 1.25 mg Bevacizumab

\begin{tabular}{|c|c|c|c|c|c|c|c|c|c|c|c|c|}
\hline & \multicolumn{4}{|c|}{ Scotopic $0 \mathrm{~dB}$} & \multicolumn{4}{|c|}{ Scotopic $25 \mathrm{~dB}$} & \multicolumn{4}{|c|}{ Photopic Cone $0 \mathrm{~dB}$} \\
\hline & $\begin{array}{c}\text { a-Wave } \\
(\mu \mathrm{V})\end{array}$ & $\begin{array}{c}\text { b-Wave } \\
(\mu \mathrm{V})\end{array}$ & $\begin{array}{c}\text { a-Wave } \\
\text { Ratio }\end{array}$ & $\begin{array}{c}\text { b-Wave } \\
\text { Ratio }\end{array}$ & $\begin{array}{c}\text { a-Wave } \\
(\mu \mathrm{V})\end{array}$ & $\begin{array}{c}\text { b-Wave } \\
(\mu \mathrm{V})\end{array}$ & $\begin{array}{c}\text { a-Wave } \\
\text { Ratio }\end{array}$ & $\begin{array}{c}\text { b-Wave } \\
\text { Ratio }\end{array}$ & $\begin{array}{c}\text { a-Wave } \\
(\mu \mathrm{V})\end{array}$ & $\begin{array}{c}\text { b-Wave } \\
(\mu \mathrm{V})\end{array}$ & $\begin{array}{c}\text { a-Wave } \\
\text { Ratio }\end{array}$ & $\begin{array}{c}\text { b-Wave } \\
\text { Ratio }\end{array}$ \\
\hline \multicolumn{13}{|l|}{ Group 1} \\
\hline Baseline & $49 \pm 19$ & $189 \pm 25$ & 0.94 & 1.10 & $11 \pm 2$ & $132 \pm 39$ & 1.07 & 0.96 & $10 \pm 2$ & $59 \pm 20$ & 1.02 & 0.94 \\
\hline Day 14 & $32 \pm 10$ & $202 \pm 19$ & 0.91 & 0.95 & $12 \pm 2$ & $143 \pm 37$ & 1.02 & 0.96 & $11 \pm 3$ & $71 \pm 27$ & 1.06 & 0.87 \\
\hline$P$ & 0.138 & 0.116 & 0.686 & 0.249 & 0.892 & 0.753 & 0.686 & 0.917 & 0.336 & 0.345 & 0.753 & 0.917 \\
\hline \multicolumn{13}{|l|}{ Group 2} \\
\hline Baseline & $43 \pm 10$ & $178 \pm 39$ & 0.94 & 1.11 & $11.5 \pm 2$ & $152 \pm 31$ & 1.03 & 0.95 & $10 \pm 1.1$ & $67 \pm 20$ & 1.02 & 0.94 \\
\hline Day 14 & $37 \pm 8$ & $211 \pm 10$ & 0.96 & 0.95 & $12.5 \pm 2$ & $170 \pm 27$ & 0.96 & 0.96 & $10.6 \pm 2$ & $83 \pm 14$ & 1.00 & 0.87 \\
\hline Day 28 & $37 \pm 10$ & $217 \pm 18$ & 1.19 & 1.09 & $12 \pm 4$ & $156 \pm 28$ & 1.17 & 1.10 & $11 \pm 1.8$ & $87 \pm 13$ & 1.06 & 1.18 \\
\hline$P$ & 0.867 & 0.074 & 0.738 & 0.223 & 0.522 & 0.065 & 0.738 & 0.311 & 0.878 & 0.066 & 0.223 & 0.846 \\
\hline
\end{tabular}

period of 8 minutes of adaptation. Interelectrode impedance was controlled automatically.

Electroretinographic analysis was based on amplitude measurements of the a- and b-waves. Amplitudes were measured from baseline to cornea-negative peak for the a-wave and from the latter (or baseline, if absent) to the cornea-positive peak for the b-wave. To minimize the effect of individual and daily variation on the ERG, the ratio of study eye b-wave amplitude to the control eye b- wave amplitude was calculated. This ratio was also calculated for a-wave amplitude.

Visual Evoked Responses. Flash VEP was elicited with the electrophysiology system (Vision Monitor Electrophysiology Model MonElec2; Metrovision). A stainless-steel needle as the active electrode was placed under the skin in the occipital area. The reference and ground electrodes were inserted in the ear and under the skin of the forehead region, respectively. Monocular recordings were performed and contralateral eyes were occluded while the tested eye was recorded. The VEP signals were obtained from a Universal Ganzfeld optoelectronic stimulator and amplified using a bioelectric signal amplifier $(\times 12,500)$ and filtered at 1 to $35 \mathrm{~Hz}$. Data were collected, stored and analyzed using a microcomputer-designed software and data acquisition hardware electronic control unit. The identifiable wave of the flash VEP was an initial negative wave followed by a prominent positive wave. The VEP amplitude and implicit time were measured.

\section{Histopathologic Analysis}

After final examination by ophthalmoscopy and electrophysiology, the animals were killed by intraperitoneal injection of a lethal overdose of pentobarbital. The eyes were enucleated with careful manipulation to preserve globe integrity. Each eye was immediately placed in neutral formalin solution for light microscopic examination and in $2.5 \%$ glutaraldehyde in $0.1 \mathrm{M}$ phosphate buffer for electron microscopic examination.

Light Microscopic Evaluation. Four eyes were fixed in neutral formalin solution for 7 days and immersed in sucrose solution
(30\%) for easy dissection, dehydrated in a series of graded alcohols, and embedded in paraffin. Sections were obtained from cuts through the whole globe oriented along the optic nerve and medullary ray. Sections of $5-\mu \mathrm{m}$ thickness were obtained by using a microtome, stained with hematoxylin-eosin (H\&E). Slides were examined under light microscope.

Electron Microscopic Evaluation. One eye in each group was fixed in $2.5 \%$ glutaraldehyde buffered with 0.13 M Sorensen's phosphate buffer at $4^{\circ} \mathrm{C}$ for a day. The eye was dissected after the fixation. Samples of the peripheral and central retina were taken from the tissue and fixed in $2.5 \%$ glutaraldehyde for 2 hours. The samples were postfixed with $1 \%$ osmium tetroxide in the same buffer at $4^{\circ} \mathrm{C}$ for 1 hour, dehydrated in a series of graded ethanols, and infiltrated at room temperature with propylene oxide and embedded epoxy resin. Semithin and ultrathin sections were cut with a glass knife on an ultramicrotome. Semithin sections were stained with toluidine blue. Ultrathin sections were mounted on 100-mesh copper grids and stained with $4 \%$ aqueous uranyl acetate for 30min and Reynold's lead citrate solution for 10 minutes. The sections were examined with a transmission electron microscope (100 SX; JEOL, Tokyo, Japan).

Antigen Retrieval. To obtain better and more specific staining, the antigen retrieval method was used: sections were mounted on poly-L[SCAP]-lysine-coated slides. They were deparaffinized with xylol, passed through graded alcohols, and rinsed successively in distilled water. This treatment was followed by the use of $1 \%$ hydrogen peroxide to block the endogenous peroxidase; the sections were washed and processed for the antigen retrieval procedure which was performed in a water bath at $90^{\circ} \mathrm{C}$ for 15 minutes.

Immunobistochemistry. After the blocking incubation in normal horse serum (10\% in Tris-HCl buffer containing $0.1 \%$ Na-azide and $0.2 \%$ Triton $\mathrm{X}-100$ ), sections were incubated for 1 hour at room temperature (RT) during the primary antibody incubations in rabbit anti-caspase-3, caspase-9 and bax (Santa Cruz Biotechnology, Santa Cruz, CA). The antibodies were diluted in the above blocking buffer at

TABLE 3. Early- and Late-term ERG Results under Scotopic and Photopic Conditions in Eyes Receiving 3.0 mg Bevacizumab

\begin{tabular}{|c|c|c|c|c|c|c|c|c|c|c|c|c|}
\hline & \multicolumn{4}{|c|}{ Scotopic $0 \mathrm{~dB}$} & \multicolumn{4}{|c|}{ Scotopic 25 dB } & \multicolumn{4}{|c|}{ Photopic Cone $0 \mathrm{~dB}$} \\
\hline & $\begin{array}{c}\text { a-Wave } \\
(\mu \mathrm{V})\end{array}$ & $\begin{array}{c}\text { b-Wave } \\
(\mu \mathrm{V})\end{array}$ & $\begin{array}{c}\text { a-Wave } \\
\text { Ratio }\end{array}$ & $\begin{array}{c}\text { b-Wave } \\
\text { Ratio }\end{array}$ & $\begin{array}{c}\text { a-Wave } \\
(\mu V)\end{array}$ & $\begin{array}{c}\text { b-Wave } \\
(\mu \mathrm{V})\end{array}$ & $\begin{array}{c}\text { a-Wave } \\
\text { Ratio }\end{array}$ & $\begin{array}{c}\text { b-Wave } \\
\text { Ratio }\end{array}$ & $\begin{array}{c}\text { a-Wave } \\
(\mu V)\end{array}$ & $\begin{array}{c}\text { b-Wave } \\
(\mu \mathrm{V})\end{array}$ & $\begin{array}{c}\text { a-Wave } \\
\text { Ratio }\end{array}$ & $\begin{array}{c}\text { b-Wave } \\
\text { Ratio }\end{array}$ \\
\hline \multicolumn{13}{|l|}{ Group 3} \\
\hline Baseline & $46 \pm 10$ & $176 \pm 41$ & 1.13 & 1.10 & $13 \pm 4$ & $144 \pm 57$ & 1.16 & 1.17 & $11 \pm 2$ & $79 \pm 14$ & 1.01 & 1.25 \\
\hline Day 14 & $46 \pm 7$ & $209 \pm 46$ & 1.13 & 1.01 & $12 \pm 3$ & $156 \pm 41$ & 0.96 & 0.97 & $10 \pm 2$ & $82 \pm 21$ & 0.99 & 1.00 \\
\hline$P$ & 0.917 & 0.173 & 0.463 & 0.600 & 0.599 & 0.917 & 0.225 & 0.345 & 0.785 & 0.599 & 0.893 & 0.463 \\
\hline \multicolumn{13}{|l|}{ Group 4} \\
\hline Baseline & $36 \pm 12$ & $181 \pm 34$ & 1.10 & 1.08 & $10 \pm 1.6$ & $109 \pm 24$ & 1.12 & 1.13 & $11.3 \pm 2.0$ & $75 \pm 30$ & 1.01 & 1.14 \\
\hline Day 14 & $41 \pm 6$ & $230 \pm 29$ & 1.12 & 1.01 & $14.6 \pm 4$ & $170 \pm 27$ & 0.94 & 0.96 & $11.0 \pm 1.8$ & $84 \pm 12$ & 0.94 & 0.95 \\
\hline Day 28 & $37 \pm 6$ & $240 \pm 38$ & 0.85 & 1.16 & $14.5 \pm 4$ & $156 \pm 28$ & 1.21 & 0.92 & $11.6 \pm 1.7$ & $78 \pm 9$ & 1.05 & 0.97 \\
\hline$P$ & 0.172 & 0.076 & 0.115 & 0.513 & 0.165 & 0.097 & 0.247 & 0.115 & 0.939 & 0.819 & 0.878 & 0.846 \\
\hline
\end{tabular}


A Group $11.25 \mathrm{mg}$ Day 14 Scotopic $0 \mathrm{~dB}$

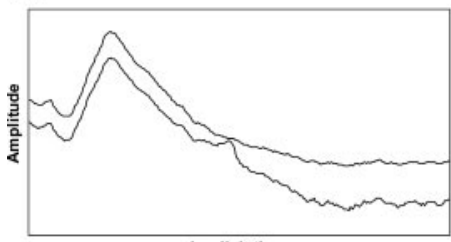

Implicit time

D Group $21.25 \mathrm{mg}$ Day 28 Scotopic $0 \mathrm{~dB}$

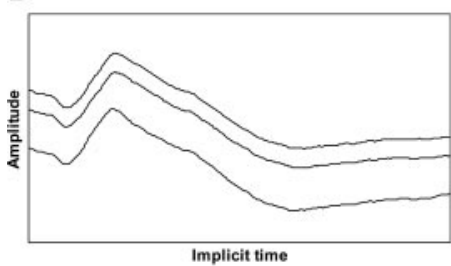

B

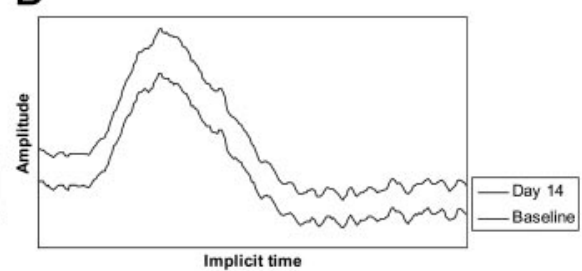

E

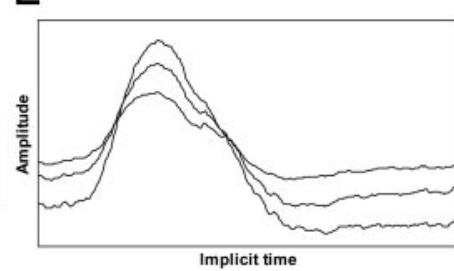

C

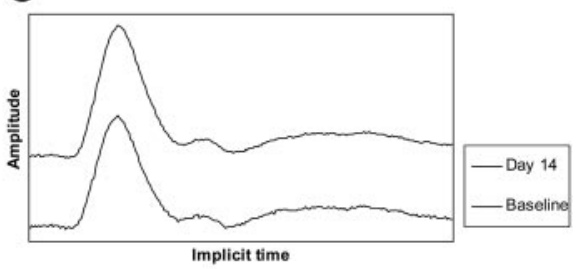

F

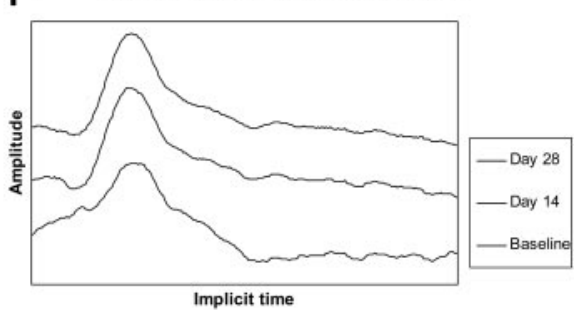

FigURE 1. Electroretinographic recordings under scotopic ( 0 and $25 \mathrm{~dB})$ and photopic $(0 \mathrm{~dB})$ conditions in eyes receiving $1.25 \mathrm{mg}$ bevacizumab in groups $1(\mathbf{A}-\mathbf{C})$ and $2(\mathbf{D}-\mathbf{F})$.

a dilution of 1:100, 1:100, 1:250 and 1:50, respectively. The incubation was terminated by three washes in Tris- $\mathrm{HCl}$ buffer, and the sections were then incubated for 60 minutes in affinity-purified and crossabsorbed biotin-conjugated donkey anti-rabbit (1:250; Jackson ImmunoResearch Laboratories, West Grove, PA). Then the sections were processed for bright-field immunohistochemistry (Elite ABC Kit; Vector Laboratories, Burlingame, CA) according to the instructions of the manufacturer. To visualize the antigen-antibody complex, diamino benzidine (DAB) was used as the chromogen. After several washes in Tris-HCl, sections were dehydrated in graded alcohol, cleared in xylol, mounted, and visualized with a photomicroscope (BX-50; Olympus, Tokyo, Japan).

\section{Statistical Analysis}

Statistical analysis was performed (SPSS, ver. 13.0; SPSS, Chicago, IL). The Mann-Whitney test and Wilcoxon matched-pair signed rank test were used to calculate potential ERG differences between control and study eyes before injection and before and after injection in the control and study eyes. IOP and CCT differences between before and after injection were also evaluated by Wilcoxon matched-pair signed rank test. A value of $P<0.05$ was considered statistically significant.

\section{Results}

\section{Clinical Evaluation}

Bevacizumab was tolerated well. No clinical signs or changes in food consumption or body weight attributable to the drug were observed.

Slit Lamp Examination. The conjunctiva and cornea were apparently normal with anterior segment examinations. No conjunctival hyperemia or corneal epithelial, stromal, or endothelial changes were observed in either early or late term. Anterior chamber reaction with ciliary injection was seen in one eye receiving a low dose of bevacizumab in the short term (day 14). No anterior vitreous cells were detected on biomicroscopic examination. A few fibrotic membrane remnants were seen in the pupillary margin. No other uveitic reaction was seen in either the low-dose or the high-dose group. No iris abnormality of color or shape was observed in any eye in any of the groups. No change in crystalline lens was observed in either the short or long term.

IOP Changes. No significant elevation of intraocular pressures was noted in eyes injected with bevacizumab 1.25 or $3.00 \mathrm{mg}$ when compared with baseline values. The mean IOP
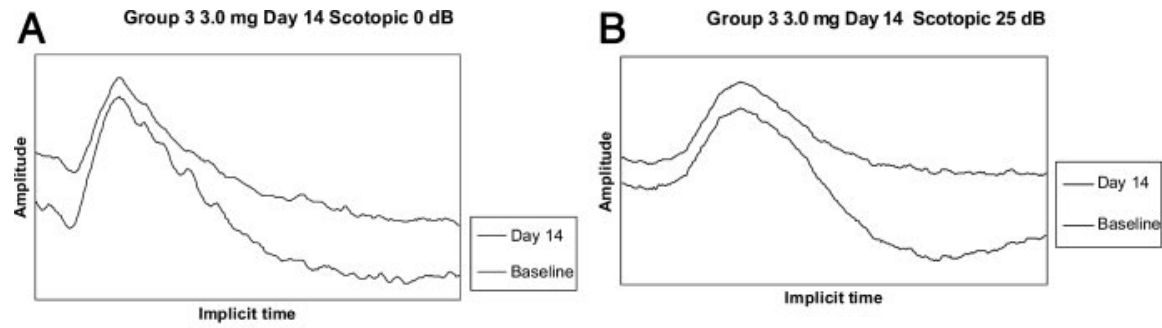
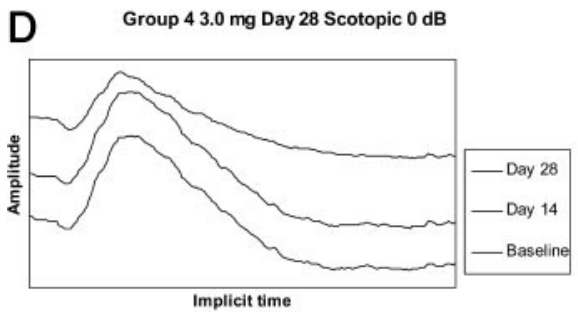

E
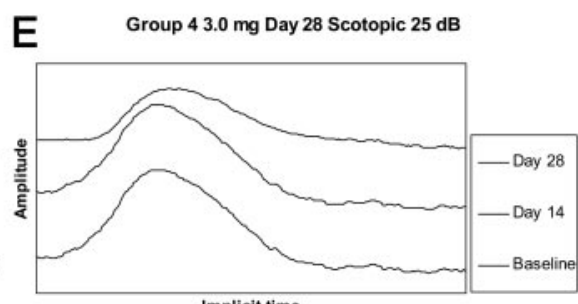

Implicit time

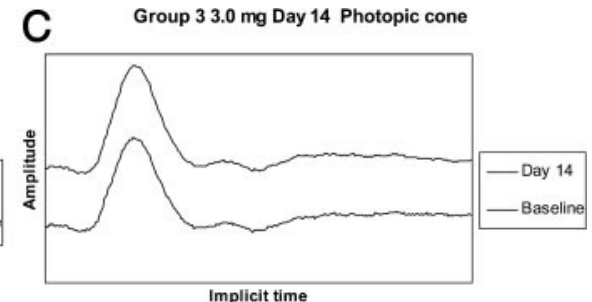

F $\quad$ Group $43.0 \mathrm{mg}$ Day 28 Photopic cone

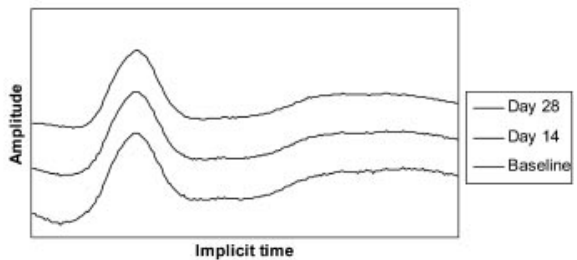

FigURE 2. Electroretinographic recordings under scotopic $(0$ and $25 \mathrm{~dB})$ and photopic $(0 \mathrm{~dB})$ conditions in eyes receiving $3.0 \mathrm{mg}$ bevacizumab in groups $3(\mathbf{A}-\mathbf{C})$ and $4(\mathbf{D}-\mathbf{F})$. 

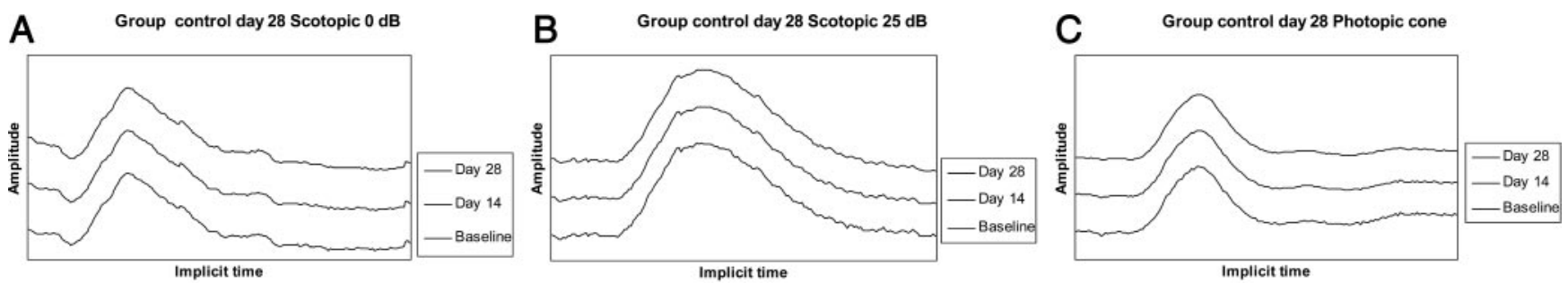

FIGURE 3. Electroretinographic recordings under (A) scotopic ( 0 and $25 \mathrm{~dB})$ and $(\mathbf{B})$ photopic $(0 \mathrm{~dB})$ conditions in eyes receiving $0.12 \mathrm{~mL}$ saline in the (C) control (fellow eyes in the group 4) eye.

values measured at baseline, early and late terms were $12.5 \pm$ $1.8,12.8 \pm 1.9$, and $13.1 \pm 1.1 \mathrm{~mm} \mathrm{Hg}$, respectively, in group 2 ; and $13.0 \pm 2.0,12.8 \pm 0.9$, and $13.5 \pm 1.3 \mathrm{~mm} \mathrm{Hg}$, respectively, in group 4 . No statistically significant difference in IOP was detected between baseline, days 14 and $28(P>$ 0.05 for all groups).

Central Corneal Thickness. Baseline CCT was between $353 \pm 21$ and $360 \pm 16 \mu \mathrm{m}$ between groups. Mean CCT was between $339 \pm 17$ and $365 \pm 17 \mu \mathrm{m}$ on day 14 . Mean CCT was $345 \pm 23$ and $354 \pm 20 \mu \mathrm{m}$ in groups 2 and 4 at day 28 . No significant alteration of CCT was noted in eyes injected with 1.25 or $3.00 \mathrm{mg}$ bevacizumab when compared with baseline thickness $(P>0.05$ for all groups).

Fundus Examination and FFA. No apparent disease of the vitreous, retina, or choroid was observed by ophthalmoscopy or fundus photography. The vitreous demonstrated no opacities or degeneration. Fundus fluorescein angiography taken in one animal in each group showed no sign of changes in retinal or choroidal perfusion.

\section{Electrophysiology}

The primary outcome variables were changes from baseline in a- and b-wave amplitudes. Differences between the two eyes in change of amplitudes were also assessed.

Electroretinography. ERG was performed as an objective assessment of retinal function in bevacizumab-injected eyes. In the statistical analysis of the baseline ERG, there were no significant differences between the study eyes and control eyes
$(P>0.05)$. No statistically significant change was found in aand b-wave amplitudes between baseline and day 14 for group 1 or baseline and day 28 for group 2. In groups 1 and 2, the ratios of a- and b-waves were quite close to 1 , and no statistically significant change was detected after the injection. In group 2, differences in scotopic 25 and $0 \mathrm{~dB}$ and photopic cone $0 \mathrm{~dB}$ b-wave amplitudes were close to statistical significance, probably because of the increase in amplitudes in bwaves. As this increase also developed in the contralateral eyes, the b-wave ratio did not change (Table 2). There was no statistically significant difference in a- and b- wave amplitudes between baseline and day 14 in group 3, nor was there any between baseline and day 28 in group 4 (Table 3 ). Both a- and b-wave ratios were close to 1 and did not show any statistically significant difference. In groups 3 and 4 , the b-wave amplitudes obtained by scotopic 25 and $0 \mathrm{~dB}$ were close to the level of statistical significance, but this is thought to be due to the increase in amplitudes, as in groups 1 and 2. An example of ERG recordings in the groups is presented in Figures 1, 2, and 3.

Visual Evoked Responses. Flash VEP responses were elicited by bright white stimuli in two eyes in each group. Good responses with a typical VEP pattern, which consisted of a negative wave followed by a positive wave after the light stimulus, were elicited from all eyes in which VEP was performed. The responses obtained from recordings at baseline and days 14 and 28 did not show any difference suggesting any change in favor of toxicity. In group 4 , whereas baseline VEP wave amplitude was $4.5 \mu \mathrm{V}$, and implicit time was $65 \mathrm{~ms}$, at
FigURE 4. (A) Localized inflammation in the ciliary body in an eye receiving $1.25 \mathrm{mg}$ bevacizumab. (B) The histopathologic section of the retina in the late term from the highdose group. (C) The histopathologic section of the central retina in the late term from high-dose group. (D) The histopathologic section of the peripheral retina in the late term from the high-dose group $(3.0 \mathrm{mg}$ intravitreal bevacizumab; toluidine blue). (A, B) H\&E; (C, D) toluidine blue. Magnification: $(\mathbf{A}) \times 10$; $(\mathbf{B}-\mathbf{D})$ $\times 40$.

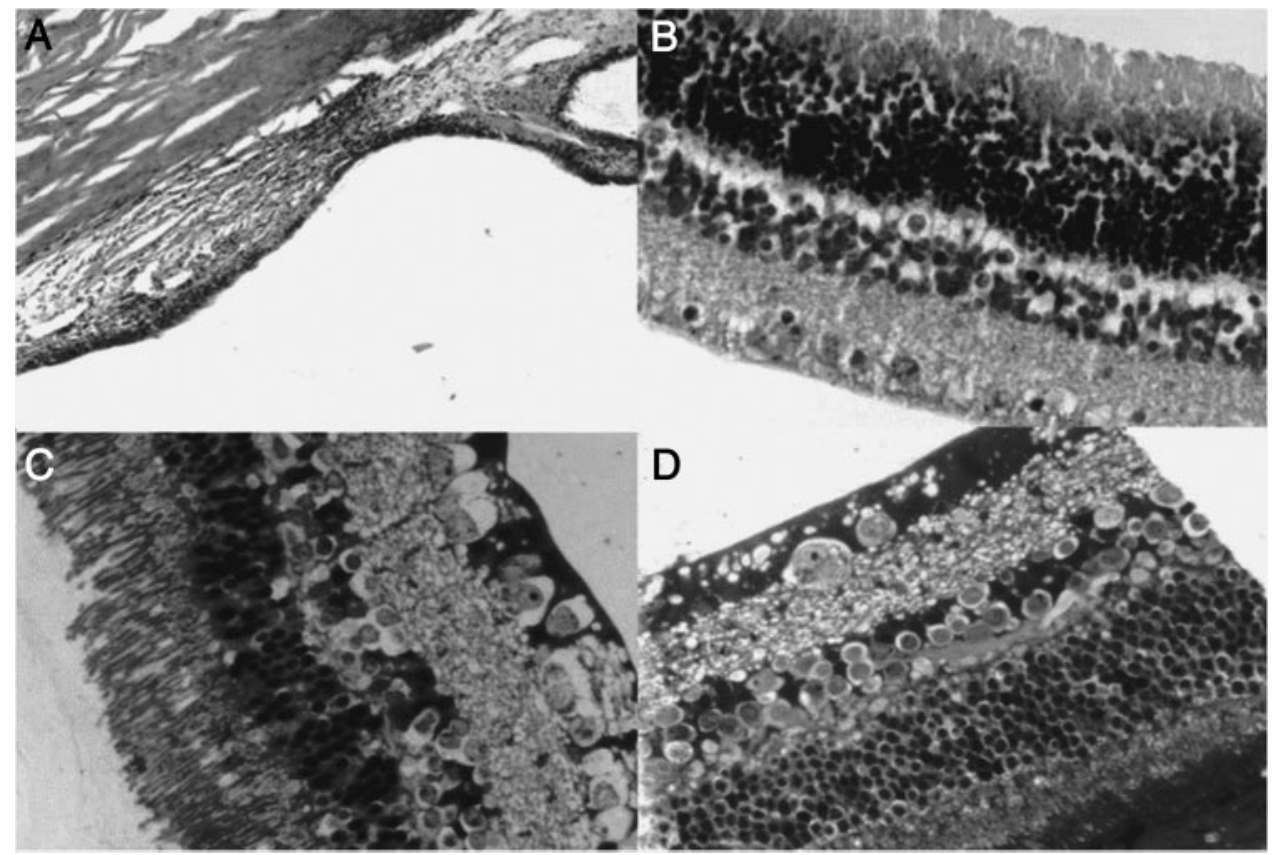




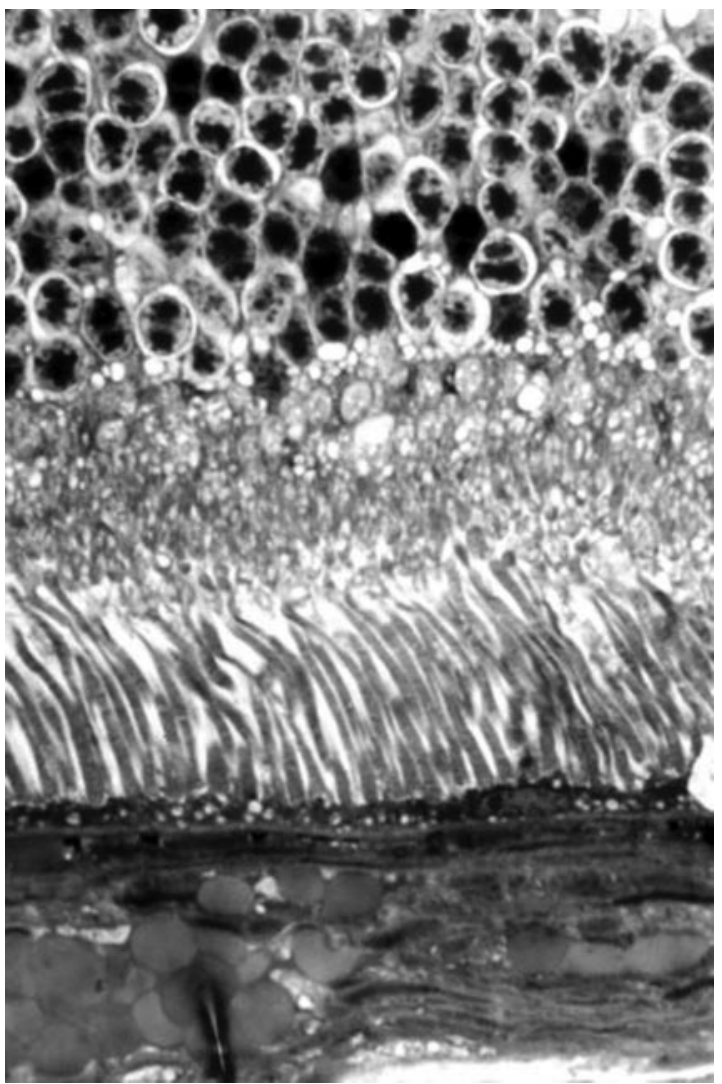

FIGURE 5. Vacuolization in the inner segments of photoreceptor layer taken from peripheral retina from the high-dose group in the late-term (toluidine blue). Magnification, $\times 100$.

day $14 \mathrm{VEP}$ wave amplitude was $4.8 \mu \mathrm{V}$, and implicit time was $76 \mathrm{~ms}$; and at day 28, VEP wave amplitude was $5.6 \mu \mathrm{V}$, and implicit time was $72 \mathrm{~ms}$. The results from the recordings in the control eyes were similar. The data obtained from VEP recordings were not analyzed, because of the limited number of eyes.

\section{Histopathology}

Light Microscopy. The histology of both treated and control eyes after intravitreal administration of bevacizumab 1.25 or $3.00 \mathrm{mg}$ was not distinguishable and showed no anatomic sign of toxicity. Quantification of retinal layers demonstrated no difference in either group.

For the light microscopic slides, the histopathologic appearance of the cornea, iris, retina, choroids, sclera, and optic nerve was normal in both control and experimental groups. One eye in the $1.25-\mathrm{mg}$ dose group had some inflammatory cells in the conjunctiva and ciliary body (Fig. 4A). There was no sign of morphologic alteration in any of the control eyes. No sign of retinal necrosis, cystic degeneration, or hypocellularity of the nuclear layer was observed in any of the groups (Fig. 4B).

When the semithin sections were evaluated, all groups had normal morphology. No sign of degeneration, thinness, dissolution, or loss in the layers of either central or peripheral retina was detected (Figs. 4C, 4D). Some vacuolization in the inner segments of photoreceptor cells was observed in the central and peripheral retina in both the low- and high-dose (Fig. 5) groups.

Electron Microscopy. Ultrastructural morphology was normal in the retinal layers of the ultrathin sections from the control groups. In the inner and outer segments of the photo- receptor layers, especially mitochondria in the photoreceptor inner segments from the control group exhibited normal morphology with well-defined cristae (Fig. 6A). The most obvious ultrastructural change observed in the retina of the experimental groups (1.25- and 3-mg dose groups) was swelling and disruption of mitochondria in the inner segments of the photoreceptors (Figs. 6B, 6C). Some mitochondria were swollen and contained expanded cristae; other mitochondria were disrupted and showed no evidence of cristae. The outer segments
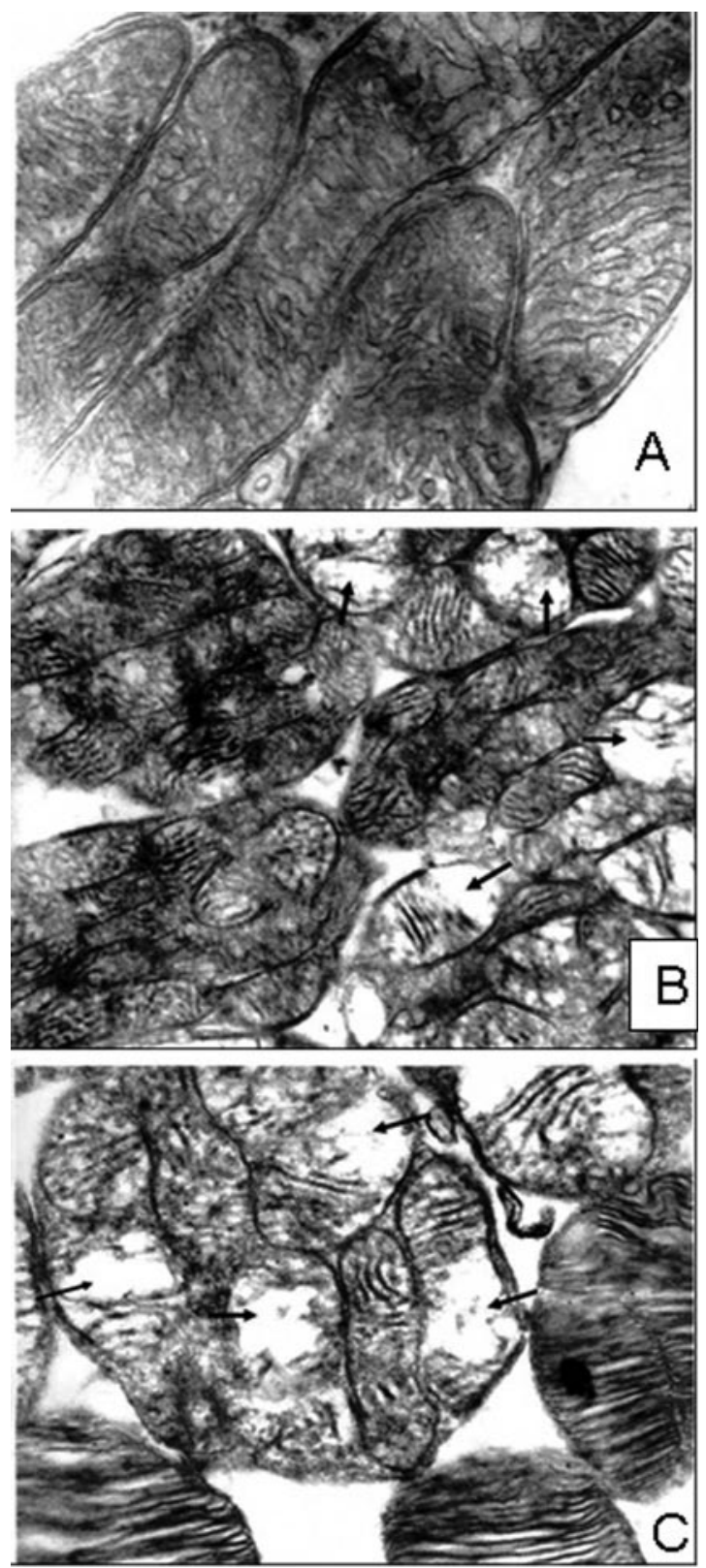

FiguRE 6. (A) Normal mitochondria and cristae in the inner segments of the photoreceptors in an eye from the control group. (B) Swelling and disruption in the mitochondria and destruction in cristae in the inner segments of the photoreceptors were observed in the low-dose group (1.25 mg intravitreal bevacizumab). Arrows: abnormal mitochondrial morphology in photoreceptor inner segments. (C) Swelling and disruption in the mitochondria and destruction in cristae in the inner segments of the photoreceptors in the high-dose group $(3.0 \mathrm{mg}$ intravitreal bevacizumab). Arrows: abnormal mitochondrial morphology in photoreceptor inner segments. Magnification: (A) $\times 40,000$; (B) $\times 12,000 ;(C) \times 20,000$. 


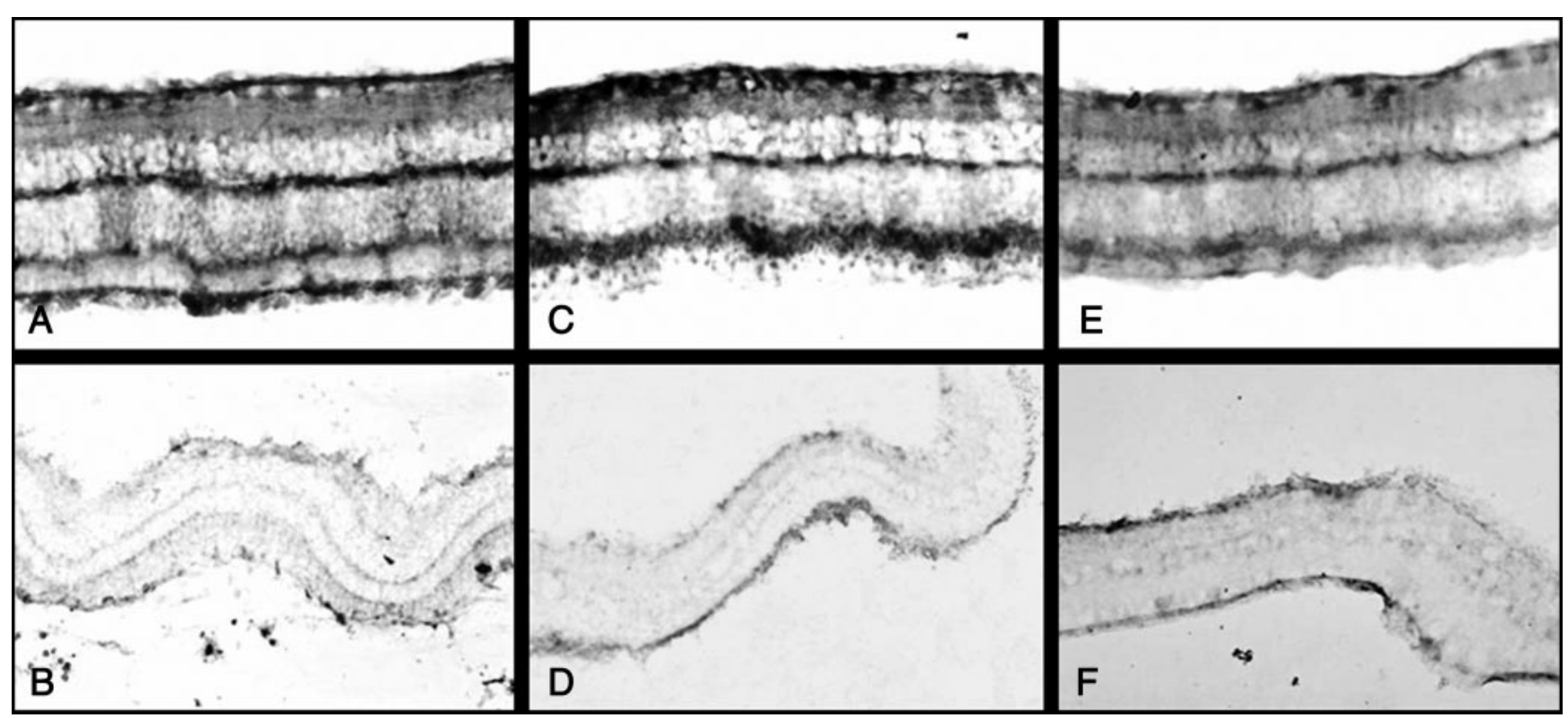

FIGURE 7. Bax immunohistochemistry staining in group 4 (A) and the control (B). Caspase-3 immunohistochemistry staining in group 4 (C) and the control (D). Caspase-9 immunohistochemistry staining in group $4(\mathbf{E})$ and the control (F). Extensive staining in the study eyes showed apoptotic expression. The control eyes showed minimal staining.

of the photoreceptors had normal ultrastructural morphology. Other layers of the retina were evaluated as normal in all groups. In immunohistochemical staining, caspase-3, caspase-9, and bax protein expressions were intensively positive in outer plexiform, outer nuclear and photoreceptor layers in all study eyes (Figs. 7A, 7C, 7E). The control groups showed minimal staining $(7 \mathrm{~B}, 7 \mathrm{D}, 7 \mathrm{~F})$.

\section{Discussion}

In our study, we sought to test the possible toxicity of intravitreal bevacizumab on intraocular tissues, and we performed electrophysiological testing for functional damage to the retina and histopathologic examination, to determine any structural and ultrastructural changes in the retinal layers.

One animal demonstrated $2+$ cells and faint flare on day 14 in our study. No other studies have reported inflammation in rabbit eyes, and this may have been an individual response by that particular rabbit and is unlikely to be dose related, as that rabbit was in the low-dose group. ${ }^{29-32}$ This finding should alert clinicians that anterior segment uveitic reaction may be seen in some cases. One study reported some inflammatory cells in the vitreous in one eye on histologic examination. ${ }^{30}$ It was suggested that the lack of inflammatory response in the rabbit eye, which is more prone to such inflammation than the human eye, may predict the lack of inflammation in human eyes as well. ${ }^{29}$ No adverse effects on the crystalline lens were observed in our study. The cornea also remained clear in both the low- and high-dose groups and the measurements of corneal thickness did not reveal any toxicity to the corneal endothelium. Intracameral injection of 0.1 and $0.2 \mathrm{~mL}$ bevacizumab did not cause any change in endothelial cell count or shape when evaluated by specular microscopy in a rabbit study (MorenoParamo D, et al. IOVS 2006; 47:ARVO E-Abstract 3236). No significant elevation of intraocular pressure was observed 14 or 28 days after bevacizumab injections in our study.

Our data on a- and b-wave ratios may provoke debate. If there is systemic absorption of bevacizumab, then use of the contralateral eye as a control may not be adequate for electrophysiological experiments. However, we also included a- and b-wave changes compared with preinjections. Our electrophysiological data was consistent with the results of other studies. ${ }^{29-32}$ Manzano et al. ${ }^{30}$ reported no toxic side effects with bevacizumab at different doses with $0.5,1.00,2.5$, and $5.00 \mathrm{mg}$. Shahar et al. ${ }^{29}$ reported nontoxicity with $2.5 \mathrm{mg}$ intravitreal bevacizumab by ERG and VEP in both the short and long term. In our study, no sign of toxicity of the ganglion cell layer or the retinal nerve fiber layer was detected by VEP recordings in either low or high doses. One electrophysiological study in humans also suggested that the intravitreal application of bevacizumab may be safe and does not cause damage to ocular tissues. ${ }^{33}$ An electrophysiological in vitro technique in which ERG recordings were obtained as transretinal potentials using the isolated perfused vertebrate retina in bovine showed that the photoreceptor potential P III amplitude was not changed by a concentration of $0.8 \mathrm{mg} / \mathrm{mL}$ bevacizumab, but a reduction of the a-wave amplitude of $35.2 \%$ was observed during the exposure. ${ }^{34}$

Other studies with light microscopic evaluation are consistent with our histopathological results. ${ }^{30-32}$ No toxicity to retinal cells was reported, even with $5.0 \mathrm{mg}$ intravitreal bevacizumab. ${ }^{30}$ It was reported that bevacizumab at concentrations of $0.125,0.25,0.50$, and $1.0 \mathrm{mg} / \mathrm{mL}$ was safe in the short term for human cells, rat neurosensory retinal cells, and human microvascular endothelial cells in vitro. ${ }^{35}$ Bevacizumab has been reported to cause a dose-dependent suppression of DNA synthesis in choroidal endothelial cells as a result of moderate antiproliferative activity. ${ }^{36}$ It has been suggested that bevacizumab at concentrations higher than $0.8 \mathrm{mg} / \mathrm{mL}$ may be harmful to the retinal pigment epithelium and should not be used in concentrations higher than 0.25 to $0.3 \mathrm{mg} / \mathrm{mL}$ (equaling a total dose of bevacizumab of $1.25 \mathrm{mg}$ in $4 \mathrm{~mL}$ vitreous volume). ${ }^{36} \mathrm{In}$ our study, we did not observe any toxicity to RPE in rabbit eyes with electron microscopic investigation. The doses used in our study and other studies should be interpreted with attention to the 2- to 3-mL volume of the rabbit vitreous and approximately 4 to $5 \mathrm{~mL}$ of the human vitreous.

In our study, although we did not observe any histopathological changes by light microscopy, we found ultrastructural changes in mitochondria in the inner segments of the photo- 
receptors. It was difficult to interpret these findings in favor of an evident toxicity. Thus, we used caspase- 3 , caspase-9, and bax immunohistochemistry to see whether bevacizumab causes apoptosis in the photoreceptor cell layer and found that there was intensive caspase-3, caspase-9, and bax cytoplasmic protein expression especially in the photoreceptor cell layer in the study groups. Biochemical mechanisms responsible for cellular damage are fairly complex. Metabolically active cells are firstly affected by injurious stimuli. ${ }^{37}$ Photoreceptors are the most metabolically active cells in the body, and the energy required for phototransduction is derived primarily from oxidative metabolism. ${ }^{38}$ Mitochondria are the organelles that are the most important targets for the harmful stimulant, and mitochondrial morphologic changes accompany cellular damage. ${ }^{37}$ Cellular swelling, a decrease in density, the appearance of amorphous bodies rich in phospholipids, and initiation of loss of clarity of cristae are the mitochondrial alterations seen ultrastructurally in reversible cellular loss. In ultrastructurally irreversible cellular damage, cristae are indeterminable with excessive swelling of mitochondria, and intensive damage occurs to the cellular membrane. Cellular loss occurs from necrosis and/or apoptosis as a result of irreversible damage. ${ }^{37,39}$ The mitochondrion is a critical organelle during apoptosis, being required for cell death after certain death stimuli. The early stages of apoptosis take place in the mitochondrion. Mitochondrial dysfunction is a prominent component of apoptosis. VEGF is a highly specific mitogen for vascular endothelial cells. Several reports have demonstrated that it not only induces angiogenesis, but also works as a survival factor for tumor and endothelial cells, protecting them from apoptosis. ${ }^{40}$ Withdrawal of VEGF leads to endothelial cell apoptosis in vitro and in vivo. ${ }^{41}$ VEGF has neuroprotective properties that may be attributable in part to its ability to increase the survival of neurons and the proliferation of Schwann cells. VEGF isoforms of 164 and 120 have displayed a protective effect on apoptotic retinal cells in a dose-dependent manner, when administered intravitreally in a rat model of retinal ischemia-reperfusion (Shima DT, et al. IOVS 2004;45:ARVO E-Abstract 3270). The changes found in the ultrathin structure of mitochondria may show reversible cellular damage, but may also indicate early findings of apoptosis developed in photoreceptor cells. As studies indicate that some apoptosis of the retina occurs as part of normal aging, minimal staining in control eyes was also observed. Our immunohistochemical study corresponded well with the ultrastructural data. Thus, intravitreal bevacizumab may cause toxicity by apoptosis in the photoreceptor layer. In future studies, quantitative analysis should be performed to determine the extent of apoptosis.

In conclusion, although our clinical, electrophysiological and light microscopic evaluation show that intravitreally delivered bevacizumab is safe and nontoxic to the intraocular structures at both 1.25 - and $3.00-\mathrm{mg}$ doses, the issue of ultrastructural toxicity at these doses was raised with histopathologic assessment by electron microscopy and apoptotic protein expression by immunohistochemistry. In a clinical setting caution must be exercised for possible anterior segment uveitic reaction which may be dose independent. Further studies are needed to clarify the toxic side effects of intravitreal bevacizumab, especially for cumulative effects at repeated doses, before a definitive conclusion can be drawn about its safety.

\section{References}

1. D'Amore PA. Mechanisms of retinal and choroidal neovascularization. Invest Opbthalmol Vis Sci. 1994;35:3974-3979.

2. Leung DW, Cachianes G, Kuang WJ, Goeddel DV, Ferrara N. Vascular endothelial growth factor is a secreted angiogenic mitogen. Science. 1089;246:1306-1309.
3. Aiello LP, Avery RL, Arring PG, et al. Vascular endothelial growth factor in ocular fluid of patients with diabetic retinopathy and other retinal disorders. N Engl J Med. 1994;331:1480-1487.

4. Lutty GA, McLeod S, Merges C, Diggs A, Plouet J. Localization of vascular endothelial growth factor in human retina and choroid. Arch Ophthalmol. 1996;114:971-977.

5. Malecaze F, Clamens S, Simorre-Pinatel V, et al. Detection of vascular endothelial growth factor messenger RNA and vascular endothelial growth factor-like activity in proliferative diabetic retinopathy. Arch Ophthalmol. 1994;112:1476-1482.

6. Adamis AP, Miller JW, Bernal M-T, et al. Increased vascular endothelial growth factor levels in the vitreous of eyes with proliferative diabetic retinopathy. Am J Opbthalmol. 1994;118:445-450.

7. Wells J, Murthy R, Chibber R, et al. Levels of vascular endothelial growth factor are elevated in the vitreous of patients with subretinal neovascularization. Br J Opbthalmol. 1996;80:363-366.

8. Dvorak HF, Brown LF, Detmar M, Dvorak M. Vascular permeability factor/vascular endothelial growth factor, microvascular hyperpermeability, and angiogenesis. Am J Patbol. 1995;146:1029-1039.

9. Lopez PF, Sippy BD, Lambert HM, Thach AB, Hinton DR. Transdifferentiated retinal pigment epithelial cells are immunoreactive for vascular endothelial growth factor in surgically excised age-related macular degeneration-related choroidal neovascular membranes. Invest Ophthalmol Vis Sci. 1996;37:855-868.

10. Kvanta A, Algvere PV, Berglin L, et al. Subfoveal fibrovascular membranes in age-related macular degeneration express vascular endothelial growth factor. Invest Opbthalmol Vis Sci. 1996;37: 1929-1934.

11. Amano S, Rohan R, Kuroki M, Tolentino M, Adamis AP. Requirement for vascular endothelial growth factor in wound-and inflammation-related corneal neovascularization. Invest Opbthalmol Vis Sci. 1998;39:18-22.

12. Adamis AP, Shima DT, Tolentino $M$, et al. Inhibition of VEGF prevents retinal ischemia-associated iris neovascularization in a primate. Arch Opbthalmol. 1996;114:66-71.

13. Ferrara N, Hillan KJ, Novotny W. Bevacizumab (Avastin), a humanized anti-VEGF monoclonal antibody for cancer therapy. Biochem Biophys Res Commun. 2005;333:328-335.

14. Ferrara N. Vascular endothelial growth factor: basic science and clinical progress. Endocr Rev. 2004;25:581-611.

15. Zakarija A, Soff G. Update on angiogenesis inhibitors. Curr Opin Oncol. 2005;17:578-583.

16. Ng EWM, Adamis AP. Targeting angiogenesis, the underlying disorder in neovascular age-related macular degeneration $\mathrm{Can} \mathrm{JPh}$ thalmol. 2005;40:353-368.

17. Hurwitz H, Fehrenbacher L, Novotny W, et al. Bevacizumab plus irinotecan, fluorouracil, and leucovorin for metastatic colorectal cancer. N Engl J Med. 2004;350:2335-2342.

18. Shima DT, Gougos A, Miller JW, et al. Cloning and mRNA expression of vascular endothelial growth factor in ischemic retinas of Macaca fascicularis. Invest Opbthalmol Vis Sci. 1996;37:13341340.

19. Rosenfeld PJ, Moshfeghi AA, Puliafito CA. Optical coherence tomography findings after an intravitreal injection of bevacizumab for neovascular age-related macular degeneration. Ophthalmic Surg Lasers Imaging. 2005;36:331-335.

20. Rosenfeld PJ, Fung AE, Puliafito CA. Optical coherence tomography findings after an intravitreal injection of bevacizumab (Avastin ${ }^{\circledR)}$ for macular edema from central retinal vein occlusion. $O p h$ thalmic Surg Lasers Imaging. 2005;36:336-339.

21. Nyugen QD, Shah S, Tatlipinar S, et al. Bevacizumab suppresses choroidal neovascularisation caused by pathological myopia. BrJ Ophthalmol. 2005;89:1368-1370.

22. Avery RL. Regression of retinal and iris neovascularization after intravitreal bevacizumab (Avastin) treatment. Retina. 2006;26: 352-354.

23. Davidorf FH, Mouser JG, Derick RJ. Rapid improvement of rubeosis iridis from a single bevacizumab (Avastin) injection. Retina. 2006;26:354-356.

24. Mason JO, Albert MA, Vail R. Intravitreal bevacizumab (Avastin) for refractory pseudophakic cystoid macular edema. Retina. 2006;26: $356-357$. 
25. Spaide RF, Fisher YL. Intravitreal bevacizumab (Avastin) treatment of proliferative diabetic retinopathy complicated by vitreous hemorrhage. Retina. 2006;26:275-278.

26. Iturralde D, Spaide RF, Meyerle CB, et al. Intravitreal bevacizumab (Avastin) treatment of macular edema in central retinal vein occlusion: a short-term study. Retina. 2006;26:279-284.

27. Avery RL, Pieramici DJ, Rabena MD, Castellarin AA, Nasir MA, Giust MJ. Intravitreal bevacizumab (Avastin) for neovascular agerelated macular degeneration. Opbthalmology. 2006;113:363372 .

28. Rich R, Rosenfeld P, Puliafito CA. Short-term safety and efficacy of intravitreal bevacizumab (Avastin) for neovascular age-related macular degeneration. Retina. 2006;26:495-511.

29. Shahar J, Avery RL, Heilweil G, et al. Electrophysiologic and retinal penetration studies following intravitreal injection of bevacizumab (Avastin). Retina. 2006;26:262-269.

30. Manzano RPA, Peyman GA, Khan P, Kivilcim M. Testing intravitreal toxicity of bevacizumab (Avastin). Retina. 2006;26:257-261.

31. Feiner L, Barr EE, Shui YB, Holekamp NM, Brantley MA Jr. Safety of intravitreal injection of bevacizumab in rabbit eyes. Retina. 2006; 26:882-888.

32. Bakri SJ, Cameron JD, McCannel CA, Pulido JS, Marler RJ. Absence of histologic retinal toxicity of intravitreal bevacizumab in a rabbit model. Am J Opbthalmol. 2006;142:162-164.

33. Maturi RK, Bleau LA, Wilson DL. Electrophysiologic findings after intravitreal bevacizumab (Avastin) treatment. Retina. 2006;26: $270-274$
34. Luke M, Warga M, Ziemssen F, et al. Effects of bevacizumab on retinal function in isolated vertebrate retina. $\mathrm{Br} \mathrm{J} \mathrm{Ophthalmol.}$ 2006;90:1178-1182.

35. Luthra S, Narayanan R, Marques LE, et al. Evaluation of in vitro effects of bevacizumab (Avastin) on retinal pigment epithelial, neurosensory retinal, and microvascular endothelial cells. Retina. 2006;26:512-518.

36. Spitzer MS, Wallenfels-Thilo B, Sierra A, et al. Antiproliferative and cytotoxic properties of bevacizumab (Avastin) on different ocular cells. Br J Ophthalmol. 2006;90-1316-1321.

37. Howes EL, Rao NA. Basic mechanisms in pathology. In: Spencer WH, ed. Opbthalmic Patbology. 4th ed. Philadelphia: WB Saunders; 1996: 2939-2945.

38. Eels JT, Henry MM, Summerfelt P, et al. Therapeutic photobiomodulation for methanol-induced retinal toxicity. Proc Natl Acad Sci USA. 2003;100:3439-3444.

39. Mootha VK, Wei MC, Buttle KF, et al. A reversible component of mitochondrial respiratory dysfunction in apoptosis can be rescued by exogenous cytochrome C. EMBO J. 2001;20:661-671.

40. Meresman GF, Bilotas MA, Lombardi E, et al. Effect of GnRH analogues on apoptosis and release of interleukin- $1 \beta$ and vascular endothelial growth factor in endometrial cell cultures from patients with endometriosis. Hum Reprod. 2003;18:1767-1771.

41. Kasahara Y, Tuder RM, Taraseviciene-Steward L, et al. Inhibition of VEGF receptors causes lung cell apoptosis and emphysema. J Clin Invest. 2000;106:1311-1319. 